"This is the peer reviewed version of the following article: Fabry, D. C., Ronge, M. A. and Rueping, M. (2015), Immobilization and Continuous Recycling of Photoredox Catalysts in Ionic Liquids for Applications in Batch Reactions and Flow Systems: Catalytic Alkene Isomerization by Using Visible Light. Chem. Eur. J., 21: 5350-5354, which has been published in final form at DOI: 10.1002/chem.201406653. This article may be used for non-commercial purposes in accordance with Wiley Terms and Conditions for Self-Archiving.

\title{
Immobilization and Continuous Recycling of Photoredox Catalysts in Ionic Liquids for Applications in Batch Reactions and Flow Systems:Catalytic Alkene Isomerization by Using Visible Light**
}

David C. Fabry, Meria A. Ronge and Magnus Rueping*

[*] M.Sc. David C. Fabry, B.Sc M. A. Ronge, Prof. Dr. M. Rueping,*

Institute of Organic Chemistry, RWTH Aachen, Landoltweg 1, D-52074 Aachen, Deutschland

Fax: (+49) 241-80-92665

E-mail: magnus.rueping@ rwth-aachen.de

[**] The research leading to these results has received funding from the European Research Council under the European Union's Seventh Framework Programme (FP/2007-2013) / ERC Grant Agreement no. 617044 (SunCatChem).

Abstract: A catalytic (E)- to (Z)-isomerization of olefins using a photoredox catalyst under mild reaction conditions is presented. A variety of (Z)-alkenes can be prepared in presence of visible light. A new reaction system allows an easy and efficient scale-up, as well as a continuous flow process in which the photocatalyst is immobilized in an ionic liquid and continuously recycled by simple phase separation.

Stilbene and derivatives represent broadly applicable molecules which show characteristic absorption and fluorescence due to their conjugated $\pi$-system and can therefore be photochemically excited.$^{[1]}$ Owing to these properties, olefins are important additives in the production of industrial dyes, ${ }^{[2]}$ chromatic lasers ${ }^{[3]}$ and scintillators. ${ }^{[4]}$

Furthermore they continuously gain importance in the field of photophysics and photochemistry, ${ }^{[5]}$ as well as biochemistry, in which they found applications as anti-cancer drugs. ${ }^{[6]}$ Especially in the latter case, precise control of the stereochemistry regarding $(E) /(Z)$ isomers plays a crucial role. Whereas the $(E)$-alkene is readily accessible, the synthesis of the $(Z)$-isomer still poses a major challenge. Current procedures for the synthesis are Wittig reactions, ${ }^{[7]}$ the Still-Genari-modification of the HornerWadsworth-Emmons reaction, ${ }^{[8]} \mathrm{Pd}^{-{ }^{[9]}}$ und Ni-catalyzed ${ }^{[10]}$ cross couplings of $(Z)$-alkenyl halides, stereoselective reductions of alkynes by Lindlar catalysis ${ }^{[11]}$ or hydrometalations, $(Z)$-selective metathesis, ${ }^{[11]}$ the Shapiro reaction ${ }^{[12]}$ and Peterson olefinations. ${ }^{[13]}$ The highlighted reactions allow no subsequent modifications of the double bond geometry. Also, specific functional groups and electronic 
environments are required that are more energy-rich than the thermodynamically harder accessible (Z)-product.

The subsequent isomerization of double bonds via UV-light has been known for many years, but is still limited in its application due to the high energy of UV-light which can lead to numerous side reactions. Additionally, reversibility of the reactions can occur. ${ }^{[14]}$ Mechanistic studies by Caldwell revealed, ${ }^{[15]}$ that isomerizations of the double bond in $(E)$ - $\beta$-cyclopropylstyrene proceed via triplettbiradical species. Due to the ring strain radical ring-opening occurred in the case of an cyclopropyl substituent and the formation of 3-phenylcyclopentene provided proof for the biradical transition state.

In our previous efforts in the area of photoredox catalysis we concentrated on the formation of radical intermediates and applications were mainly restricted to single-electron transfers. ${ }^{[16]}$ The application of sensitizers for energy transfer processes onto the corresponding substrate was not investigated. ${ }^{[17]}$ Thus, the excitation of stilbene-systems with use of the photoredox catalyst as sensitizer was the next step.

Prior to this, Osawa and co-workers realized the isomerization of 4-cyanostilbene to the corresponding (Z)-isomer. ${ }^{[18,19]}$ In this work a ruthenium complex was attached to the nitrile-group of the substrate and then photochemically excited. Weaver and co-workers published an isomerisation of $(E)$-amino styrenes to the corresponding ( $Z$ )-products postulating amino radicals and biradicals as intermediates, respectively. ${ }^{[2]}$ In addition they reported the isomerization of styrene derivatives and allylic alcohols.

Herein, we describe a catalytic system which allows in the presence of visible light under mild reactions conditions the $(E)$ - to $(Z)$-isomerization of alkenes. The reaction tolerates different solvents and can be readily scaled-up. Considering that these products are needed in larger amounts, a convenient procedure and recycling of the catalyst is highly desirable (Scheme 1).

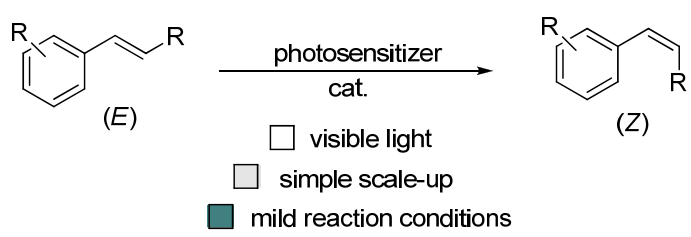

Scheme 1. Realization of a photoredox catalyzed isomerization for the synthesis of (Z)-olefins.

We here report on the E/Z-isomerization of stilbenes using readily available photoredox catalysts. First reactions in acetonitrile with $3 \mathrm{~mol} \%$ of the photosensitizer $\left[\operatorname{Ir}(\text { ppy })_{2}(\mathrm{bpy})\right] \mathrm{PF}_{6}$ showed quantitative conversions already after 18 hours (Table 1, entry 4). A broad solvent screening (see SI) revealed that high conversions can be achieved if all components are soluble in the corresponding solvent. Both acetonitrile and DMF (SI, Table 1, entry 1) and DCM (Table 1, entry 3) showed full conversions under similar conditions. In contrast to these results, lower conversions were obtained for more apolar solvents $\left(\mathrm{THF}, \mathrm{Et}_{2} \mathrm{O}\right)$ and polar protic solvents $(\mathrm{EtOH})$ since either the alkene or the photoredox catalyst were only partly soluble or completely insoluble. For the optimization of the reaction conditions different reaction scales, catalyst loadings and reactant concentrations as well as reactions times were evaluated. Quantitative conversions were obtained at 0.1 and 0.2 molar scale with $3 \mathrm{~mol} \%$ catalyst loading after 18 hours (Table 1, entry 1 and 2). Even $1.0 \mathrm{mmol}$ of the starting material 1a could be quantitatively converted into the corresponding product $\mathbf{2 a}$ after 20 hours (Table 1, entry 4). 
Table 1. Screening of reaction conditions for the isomerization reaction.

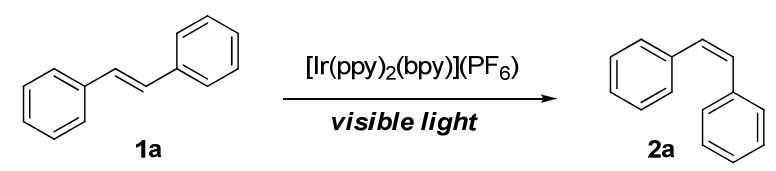

\begin{tabular}{|c|c|c|c|c|c|}
\hline Entry $^{[a]}$ & scale (mmol) & Cat loading (mol\%) & conc $(\mathrm{M})$ & time $(\mathrm{h})$ & conversion $(\%)^{[\mathrm{b}]}$ \\
\hline 1 & 0.1 & 3 & 0.1 & 18 & 99 \\
\hline 2 & 0.2 & 3 & 0.1 & 18 & 99 \\
\hline 3 & 0.2 & 1 & 0.1 & 18 & 89 \\
\hline 4 & 1.0 & 3 & 0.1 & 20 & 96 \\
\hline 5 & 10 & 0.3 & 0.1 & 48 & 62 \\
\hline 6 & 0.2 & 3 & 0.2 & 18 & 75 \\
\hline 7 & 0.2 & 3 & 0.05 & 18 & 47 \\
\hline 8 & 0.2 & 3 & 0.1 & 18 & $88^{[\mathrm{c}]}$ \\
\hline 9 & 1.0 & 3 & 0.1 & 20 & $78^{[\mathrm{c}]}$ \\
\hline 10 & 0.2 & 3 & 0.1 & 18 & $98^{[\mathrm{d}]}$ \\
\hline 11 & 1.0 & 3 & 0.1 & 20 & $61^{[\mathrm{d}]}$ \\
\hline 12 & 0.1 & 3 & 0.1 & 12 & $95^{[\mathrm{e}]}$ \\
\hline 13 & 0.1 & 3 & 0.1 & 6 & $71^{[\mathrm{e}]}$ \\
\hline 14 & 0.1 & 3 & 0.1 & 6 & 78 \\
\hline 16 & 0.1 & 3 & 0.1 & 18 & $0^{[f]}$ \\
\hline 17 & 0.1 & 3 & 0.1 & 18 & $0^{[\mathrm{g}]}$ \\
\hline 18 & 0.2 & 3 & 0.1 & 18 & $18^{[\mathrm{h}]}$ \\
\hline
\end{tabular}
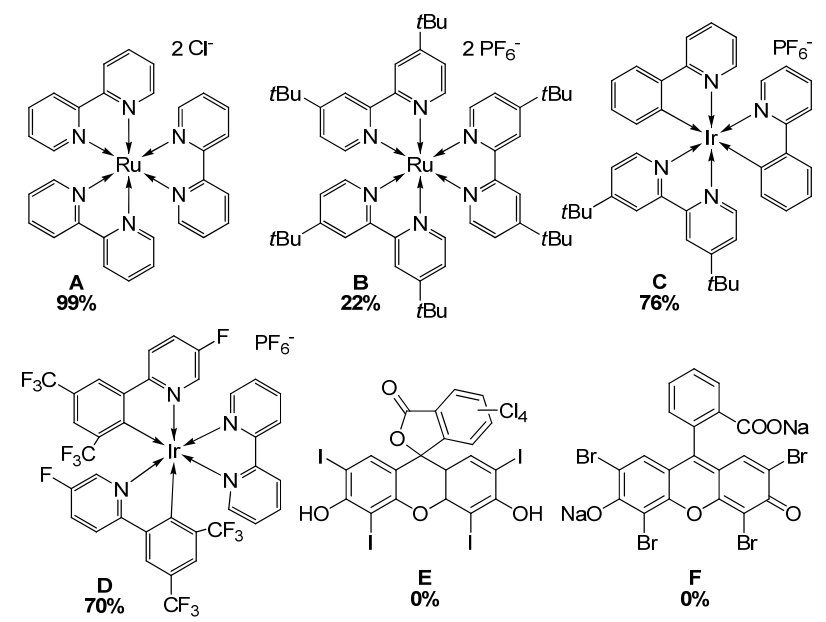
[a] Irradiation with $11 \mathrm{~W}$ lamp in $\mathrm{MeCN}$ under oxygen atmosphere [b] after chromatographic purification [c] reaction under air [d] Argon atmosphere; [e] MeCN-d 3 , [f] dark reaction; [g] if product 2a was applied as substrate no conversion to 1a was observed; [h] with 1 equiv. TEMPO.

When the catalyst loading was decreased to $1 \mathrm{~mol} \%$, still good results could be observed after 18 hours (Table 1, entry 3) whereas doubling the concentration to $0.2 \mathrm{mmol}$ scale led to decreased conversions of $75 \%$ (Table 1, entry 6). With higher dilutions $(0.05 \mathrm{M})$, lower conversions were observed (Table 1, entry 7). An increased reaction scale of $10 \mathrm{mmol}$ with only $0.3 \mathrm{~mol} \%$ catalyst led to conversions of $62 \%$ (Table 1, entry 5).

Subsequently the influence of oxygen was examined by conducting the reaction under air, resulting in $88 \%$ conversion at a $0.2 \mathrm{mmol}$ scale and $61 \%$ at $1 \mathrm{mmol}$ scale (Table 1, entry 8 and 9). Under argon atmosphere similar results were obtained (entry 10 and 11). In order to identify influences of singletoxygen, the reaction was conducted in deuterated acetonitrile. According to the theory, decreased reactivity should be obtained, but was not observed with $95 \%$ conversion (Table 1, entry 12) ). ${ }^{[21]}$ To further support this observation the reaction was stopped after 6 hours but still similar reactivities with $71 \%$ and $78 \%$ conversions were obtained, allowing the conclusion that singlet-oxygen is not playing a major role in this reaction (Table 1, entry 13 and 14). Exclusion of light led to no conversion showing the importance of visible light in this reaction (Table 1, entry 16).

Different photoredox catalysts including both, ruthenium and iridium complexes showed activity in the isomerization reaction. The $\left[\operatorname{Ir}(\mathrm{ppy})_{2}(\mathrm{bpy})\right]\left(\mathrm{PF}_{6}\right)-$ and $\left[\mathrm{Ru}(\mathrm{bpy})_{3}\right] \mathrm{Cl}_{2}$-complex were the best with $99 \%$ yield. Ir-complexes $\mathbf{C}$ and $\mathbf{D}$ led to $76 \%$ and $70 \%$ yield (Table 1, entry $\mathbf{C}$ and $\mathbf{D}$ ), respectively. Ru-complex B only showed $22 \%$ conversion. This illustrates that both sterically demanding ligands, as well as electron-withdrawing properties have a negative influence on the reaction outcome.

In the following the question arose whether the presented reaction is in fact an equilibrium which then could be adjusted either by thermodynamic or kinetic control. In order to examine if an isomerization to the $(E)$-stilbene 2a was possible $(Z)$-stilbene 2a was applied as substrate (Table 1, entry 17). No reversibility of the isomerization reaction could be detected concluding that the equilibrium is completely shifted towards the (Z)-stilbene $\mathbf{2 a}$.

At last we tried to clarify whether a radical based mechanism is operating. Addition of TEMPO led to suppression of reaction with $18 \%$ conversion (Table 1, entry 18), confirming our hypothesis. Referring to the work of Caldwell ${ }^{[15]}$ we applied cyclopropyl derivative 20 in the reaction in order to obtain data based on a "radical-clock" and therefore gain hints regarding a biradical intermediate.

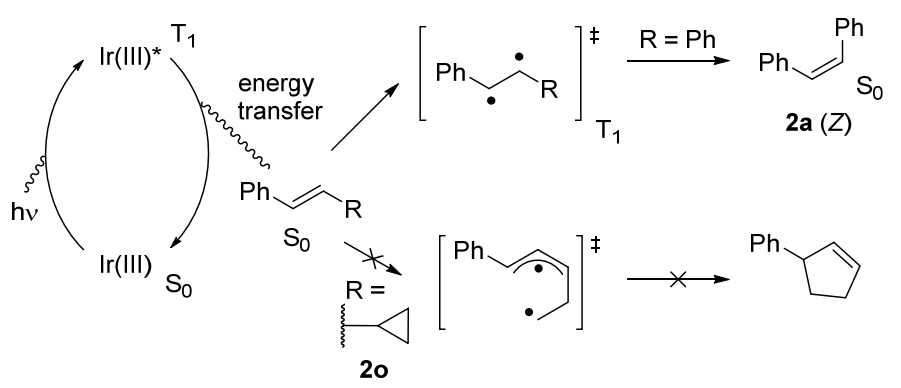

Scheme 2. Mechanistic aspects of the isomerization reaction. 
Unfortunately, the substrate turned out to be inreactive in this reaction presumably due to its $\pi$-system that leads to low energy absorbance from the photoredox catalyst.

However, all experiments together suggest an energy-transfer mechanism. The excitation of the photoredox catalyst results in a triplet state $(2.1 \mathrm{eV})^{[25]}$ from which the ground state $\mathrm{S}_{0}$ of the substrate ( $E$-isomer) 1a can be excited to its corresponding triplet state $\mathrm{T}_{1}$ by energy-transfer. Since the triplet states of $(E)$-stilbene $\mathbf{1 a}(2.2 \mathrm{eV})^{[26]}$ and $(Z)$-stilbene $\mathbf{2 a}(2.5 \mathrm{eV})^{[26]}$ differ, only the $(E)$-isomer 1a can be transferred into its triplet state. Since the corresponding $(Z)$-isomer 2a cannot accept the energy from the photosensitizer due to higher triplet states, no reversible reaction to $(E)$-stilbene 1a can take place.

Table 2. Substrate scope of the isomerization reaction ${ }^{[a]}$

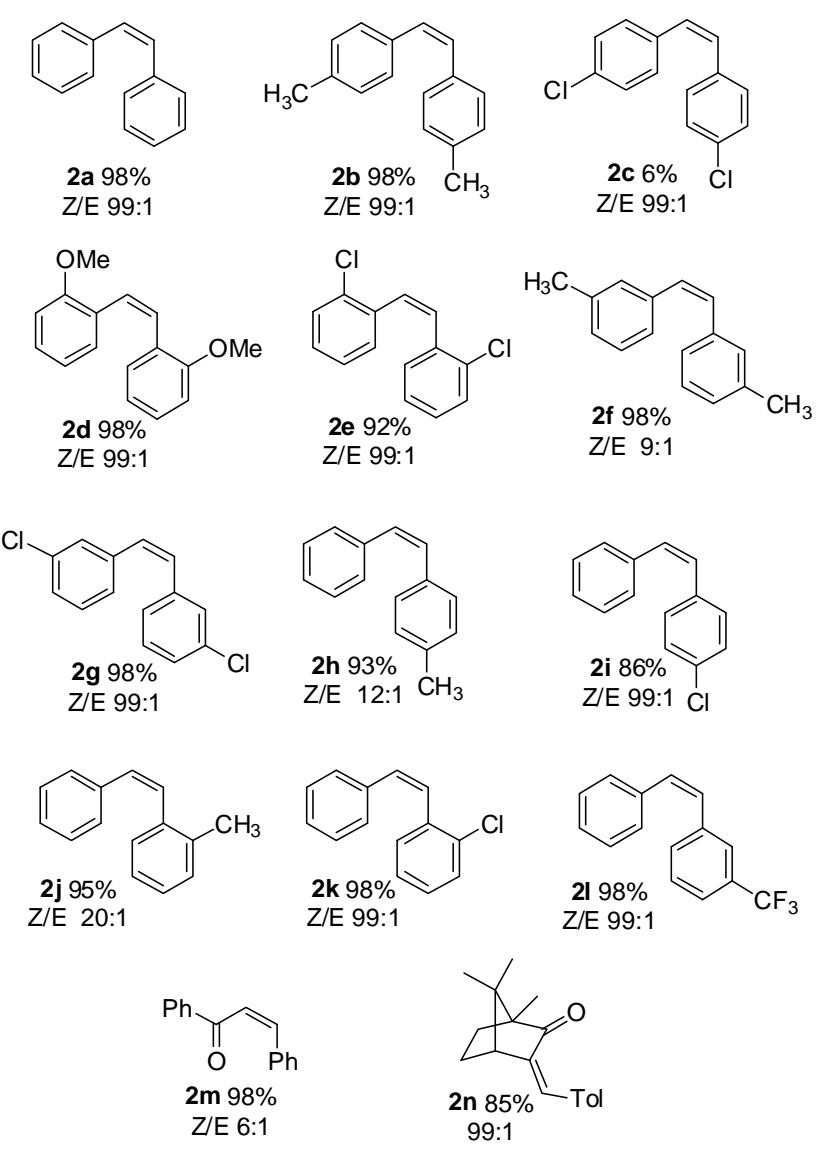

[a] $0.2 \mathrm{mmol}$ substrate 1, $3 \mathrm{~mol} \%\left[\operatorname{Ir}(\mathrm{bpy})(\mathrm{ppy})_{2}\right] \mathrm{PF}_{6}$, using a $11 \mathrm{~W}$ lamp, yields after column chromatographic purification.

Next, we evaluated the substrate scope of the developed reaction. The reaction proved to be tolerant, both with regard to different substitution patterns, as well as electronic properties of the substrates. Unsubstituted (Z)-stilbene was obtained in 98\% yield and a Z/E-ratio of 99:1. The same was observed for 4,4'-dimethylstilbene $\mathbf{2 b}$ with two electron-donating groups in para-position. When the two methyl groups were replaced by electron-withdrawing substituents such as chlorine (2c), similar yields of 96\% and a Z/E-ratio of 99:1 were obtained. Two electron-donating substituents, such as 2,2'dimethyoxy-stilbene 2d in ortho-position led to excellent yields of 98\% and a Z/E-ratio of 99:1. For 4,4'-dichlorostilbene 2e Z/E-ratios of 99:1 and slightly lower yield of $92 \%$ was obtained. A chlorine in meta-position provided the same selectivities and excellent yields of $98 \%(\mathbf{2 g})$. Methyl groups in 
meta-position led to a good yield but the $Z / E$-ratios of 9:1 varied drastically from the other substrates (2f). This is presumably caused by the fact that the triplet state energy of both $E$ - and $Z$-isomers are similar. The same seems to be applicable for mono-substitutions with $-\mathrm{CH}_{3}$ in ortho- and para-position which resulted in very good yields of 95\% (2j) and 93\% (2h) and a Z/E-ratio of 20:1 and 12:1, respectively. Also good results were obtained for the mono-substituted substrates with chlorine in para- (2i) and ortho-position (2k). Yields of $86 \%$ and $96 \%$ and $Z / E$-ratios of 99:1 were obtained in

these cases. In the same way, good results were obtained with strongly electron-withdrawing groups such as trifluoromethyl in meta-position (2l). Chalcone derivative $\mathbf{2 m}$ showed excellent conversions, however the $Z / E$-ratios of 6:1 were lower. For more complex campher derivate $2 \mathbf{n}$ excellent selectivities of $99: 1$ and a yield of $85 \%$ was obtained.

Regarding economic and ecological aspects recycling of the catalyst is indispensable. Therefore we decided to develop a new reaction technique in which a 2-phase system is applied. The photosensitizer should be, due to its charge, well absorbable in ionic liquid (IL) ${ }^{[22]}$ phase whereas the olefin should be readily separable using a corresponding apolar solvent phase. In order to test this hypothesis we conducted the isomerization of $\mathbf{1 a}$ to the corresponding (Z)-olefin 2a using a 2-phase system. Separation was readily achieved when a 2-phase system consisting of toluene/[bmim/ $\left.\mathrm{BF}_{4}\right]$ was applied. Using this protocol eight cycles were carried out using the same photocatalyst@IL system. Remarkably no loss of reactivity was observed (Table 3) clearly demonstrating the effectiveness of this new photocatalyst immobilization method.

Table 3. Immobilization of the photoredox catalyst in ionic liquids for the photoredox isomerization of stilbene 1a.

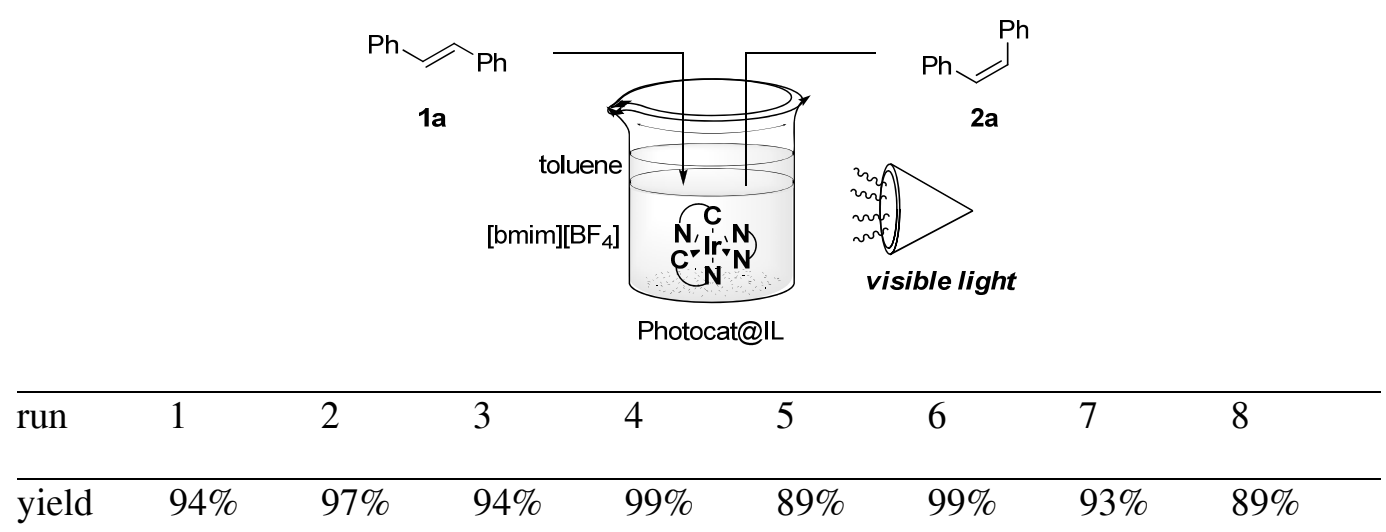

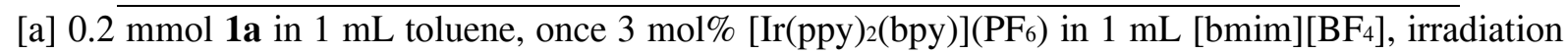
using $11 \mathrm{~W}$ lamp. [b] yields after column chromatography.

To improve this methodology even further we decided to develop a continuous flow reaction. In particular the use of a larger scale would demonstrate the applicability of this new method. Thus, we started our investigation by using a glas microreactor through which a $0.1 \mathrm{M}$ solution of stilbene 1a and $3 \mathrm{~mol} \%$ [ $\operatorname{Ir}(\mathrm{ppy})_{2}(\mathrm{bpy}) \mathrm{PF}_{6}$ was pumped under light irradiation (Table 4). The previously applied $11 \mathrm{~W}$ lamp did not show any conversions even with lower flow rates of $1 \mathrm{mLh}^{-1}$. However, with bluelight high-power LEDs flow rates up to $10 \mathrm{mLh}^{-1}$ were achieved. In contrast to the previously applied long reactions times of $18 \mathrm{~h}$, the space-time-yield could be significantly increased using the new flow system. 
Table 4. Isomerization fo stilbenes in continuous flow systems.

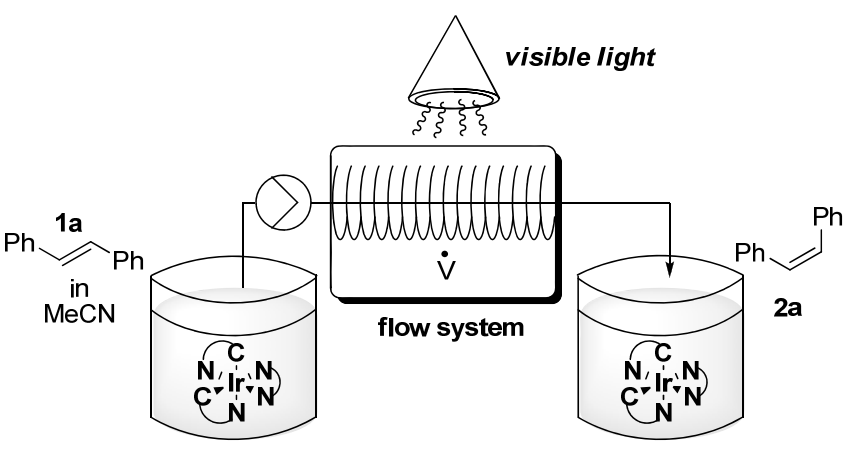

\begin{tabular}{lcc}
\hline entry & flow rate $\left[\mathrm{mLh}^{-1}\right]$ & conversion \\
\hline 1 & 2 & $92^{[\mathrm{a}]}(\%)$ \\
2 & 5 & $92^{[\mathrm{b}]}$ \\
3 & 10 & $89^{[\mathrm{b}]}$ \\
4 & 30 & $43^{[\mathrm{b}]}$ \\
5 & 50 & $24^{[\mathrm{b}]}$ \\
\hline 6 & 20 & $93^{[\mathrm{c}]}$ \\
7 & 25 & $86^{[\mathrm{cc}]}$ \\
8 & 50 & $64^{[\mathrm{cc}]}$ \\
\hline
\end{tabular}

[a] conversion via ${ }^{1} \mathrm{H}-\mathrm{NMR}$ spectroscopy. [b] $0.1 \mathrm{M}$ solution of $1 \mathrm{a}$ and $3 \mathrm{~mol} \%$ [ $\left.\operatorname{Ir}(\mathrm{ppy})_{2}(\mathrm{bpy})\right]\left(\mathrm{PF}_{6}\right)$ in $\mathrm{MeCN}$, irradiation with High Power blue LEDs, conducted in microreactor. [c] $0.1 \mathrm{M}$ solution of 1a and $3 \mathrm{~mol} \%\left[\operatorname{Ir}(\mathrm{ppy})_{2}(\mathrm{bpy})\right]\left(\mathrm{PF}_{6}\right)$ in $\mathrm{MeCN}, \mathrm{O}_{2}$-saturated; irradiation with High Power blue LEDs, conducted in mesoscale reactor.

To increase the sustainability of the system, the continuous recycling and reapplication of the precious photoredox catalyst is imperative (Scheme 3 ). This can be achieved by a immediate reuse of the photocat@IL system. After passing through the microreactor the $n$-pentane phase with stilbene 1a separated effectively from the photosensitizer@IL phase. The latter was directly pumped back into the reactor where reaction with the substrate occurs. Using this novel microflow photochemistry ${ }^{[23,24]}$ set up flow rates up to $10-20 \mathrm{mLh}^{-1}$ and quantitative conversions (1.8 g scale) were achieved without loss of photoredox catalyst.

In summary the visible light mediated E/Z-isomerization of alkenes in presence of different photosensitizers was achieved. Otherwise not-readily accessible (Z)-olefins can thus be obtained in good to very good yields. The presented catalytic isomerization represents an improved methodology if compared to conventional methods for the synthesis of $(Z)$-alkenes as it $i$ ) displays a subsequent isomerization of easily accessible $(E)$-alkenes; $i i)$ uses visible light and mild reaction conditions without use of any additives; and iii) can be conducted in continuous flow system using a new photocatalyst in ionic liquid immobilization technology. In particular, the transfer to immobilized multi-phase batch and flow system underlines the attractiveness of the presented methodology especially with regard to its synthetic application. Investigations concerning a detailed reaction mechanism and its application towards more complex syntheses is currently on-going in our group. 


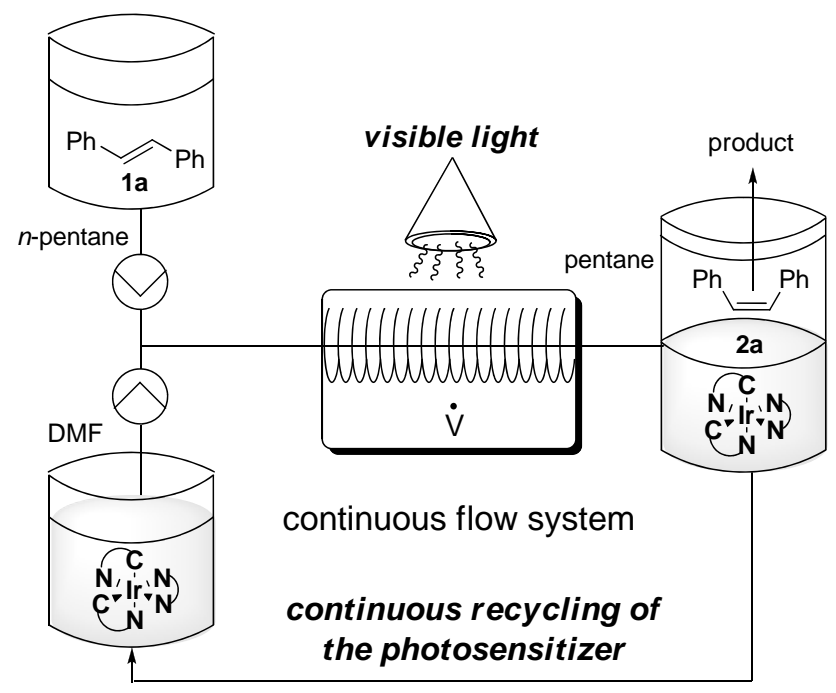

Scheme 3. 2-Phase flow system with continuous recycling of the catalyst system.

Keywords: photocatalyst, flow chemistry, ionic liquid, immobilization, isomerization

References:

[1] J. A. Sebree, T. S. Zwier, Phys ChemChemPhys 2012, 14, 173-183.

[2] D. H. Song, H. Y. Yoo, J. P. Kim, Dyes Pigm. 2007, 75, 727-731.

[3] M. Hara, S. Samori, X. Cai, M. Fujitsuka, T. Majima, J. Phys. Chem. A 2005, 109, 98319835.

[4] J. A. Brown, B. L. Goldblum, L. A. Bernstein, D. L. Bleuel, N. M. Brickner, J. A. Caggiano, B. H. Daub, G. S. Kaufman, R. Hatarik, T. W. Phillips, et al., J. Appl. Phys. 2014, 115, 193504.

[5] D. G. Whitten, Acc. Chem. Res. 1993, 26, 502-509.

[6] a) A. McCalley, S. Kaja, A. Payne, P. Koulen, Molecules 2014, 19, 7327-7340; b) R. Frazzi, M. Tigano, Int. J. Mol. Sci. 2014, 15, 4977-4993.

[7] a) A. B. Smith, T. J. Beauchamp, M. J. LaMarche, M. D. Kaufman, Y. Qiu, H. Arimoto, D. R. Jones, K. Kobayashi, J. Am. Chem. Soc. 2000, 122, 8654-8664; b) C. J. O'Brien, J. L. Tellez, Z. S. Nixon, L. J. Kang, A. L. Carter, S. R. Kunkel, K. C. Przeworski, G. A. Chass, Angew. Chem. Int. Ed. 2009, 48, 6836-6839; c) D.-J. Dong, H.-H. Li, S.-K. Tian, J. Am. Chem. Soc. 2010, 132, 5018-5020; d) P. A. Byrne, D. G. Gilheany, Chem. Soc. Rev. 2013, 42, 6670-6696.

[8] a) W. C. Still, C. Gennari, Tetrahedron Lett. 1983, 24, 4405-4408; b) H. Meier, Angew. Chem. Int. Ed. 1992, 31, 1399-1420.

[9] E.-I. Negishi, Z. Huang, G. Wang, S. Mohan, C. Wang, H. Hattori, Acc. Chem. Res. 2008, 41, 1474-1485.

[10] Z. Huang, E.-I. Negishi, J. Am. Chem. Soc. 2007, 129, 14788-14792. 
[11] S. J. Meek, R. V. O’Brien, J. Liaveria, R. R. Schrock, Nature 2011, 471, 461-466.

[12] K. Maruoka, M. Oishi, H. Yamamoto, J. Am. Chem. Soc. 1996, 118, 2289-2290.

[13] L. F. van Staden, D. Gravestock, D. J. Ager, Chem. Soc. Rev. 2002, 31, 195-200.

[14] D. H. Waldeck, Chem. Rev. 1991, 91, 415-436.

[15] R. A. Caldwell, L. Zhou, J. Am. Chem. Soc. 1994, 116, 2271-2275.

[16] a) S. Zhu, A. Das, L. Bui, H. Zhou, D. P. Curran, M. Rueping, J. Am. Chem. Soc. 2013, 135, 1823-1829; b) M. Nakajima, Q. Lefebvre, M. Rueping, Chem. Commun. 2014, 50, 3619 3622.

[17] C. K. Prier, D. A. Rankic, D. W. C. MacMillan, Chem. Rev. 2013, 113, 5322-5363.

[18] M. Osawa, M. Hoshino, Y. Wakatsuki, Angew. Chem. Int. Ed 2001, 40, 3472-3474.

[19] For a $\mathrm{Cu}(\mathrm{I})$-catalyzed E/Z-isomerization of stilbene, see: S. Sakaki, I. Okitaka, K. Ohkubo, Inorg. Chem. 1984, 23, 198-203.

[20] K. Singh, S. J. Staig, J. D. Weaver, J. Am. Chem. Soc. 2014, 136, 5275-5278.

[21] a) P. B. Merkel, R. Nilsson, D. R. Kearns, J. Am. Chem. Soc. 1972, 94, 1030-1031; b) P. R. Ogilby, C. S. Foote, J. Am. Chem. Soc. 1981, 103, 1219-1221; c) P. R. Ogilby, C. S. Foote, J. Am. Chem. Soc. 1983, 105, 3423-3430.

[22] Handbook of Green Chemistry, Volume 6, Green Solvents, Ionic Liquids (Eds. P. T. Anastas, P. Wasserscheid, A. Stark), 2013, Wiley-VCH.

[23] Reviews: a) Y. Matsushita, T. Ichimura, N. Ohba, S. Kumada, K. Sakeda, T. Suzuki, H. Tanibata, T. Murata, Pure Appl. Chem. 2007, 79, 1959-1968; b) E. E. Coyle, M. Oelgemöller Photochem. Photobiol. Sci. 2008, 7, 1313-1322; c) M. Oelgemöller, O. Shvydkiv, Molecules 2011, 16, 7522-5750; d) M. Oelgemöller, A. Murata MedChem News 2012, 22, 30-40; e) J. P. Knowles, L. D. Elliott, K. I. Booker-Milburn, Beilstein J. Org. Chem. 2012, 8, 2025-2052; f) M. Oelgemöller, Chem. Eng. Technol. 2012, 35, 1144-1152; g) Y. Su, N. J. W. Straathof, V. Hessel, T. Noel, Chem. Eur. J. 2014, 20, 10562-10589; h) O. Shvydkiv, M. Oelgemöller, Microphotochemistry: Photochemical Synthesis in Microstructed Flow Reactors in CRC Handbook of Organic Photochemistry and Photobiology, (Eds. A. Griesbeck, M. Oelgemöller, F. Ghetti), chapter 6, 125-178.

[24] Selected, recent examples for photoflow chemistry: a) F. R. Bou-Hamdan, P. H. Seeberger, Chem. Sci. 2012, 3, 9785-9795; b) J. W. Tucker, Y. Zhang, T. F. Jamison, C. R. J. Stephenson, Angew. Chem. Int. Ed. 2012, 51, 4144-4147; c) R. S. Andrews, J. J. Becker, M. R. Gagné, Angew. Chem. Int. Ed. 2012, 51, 4140-4143; d) M. Neumann, K. Zeitler, Org. Lett. 2012, 14, 2658-2661; e) J. D. Nguyen, B. Reiß, C. Dai, C. R. J. Stephenson, Chem. Commun. 2013, 49, 4352-4354.

[25] K. N. Swanik, S. Ladouceur, E. Zysman-Colman, Z. Ding, RSC Adv., 2013, 3, 19961-19964.

[26] W. G. Herkstroeter, D. S. McClure, J. Am. Chem. Soc 1968, 90, 4522-4527. 